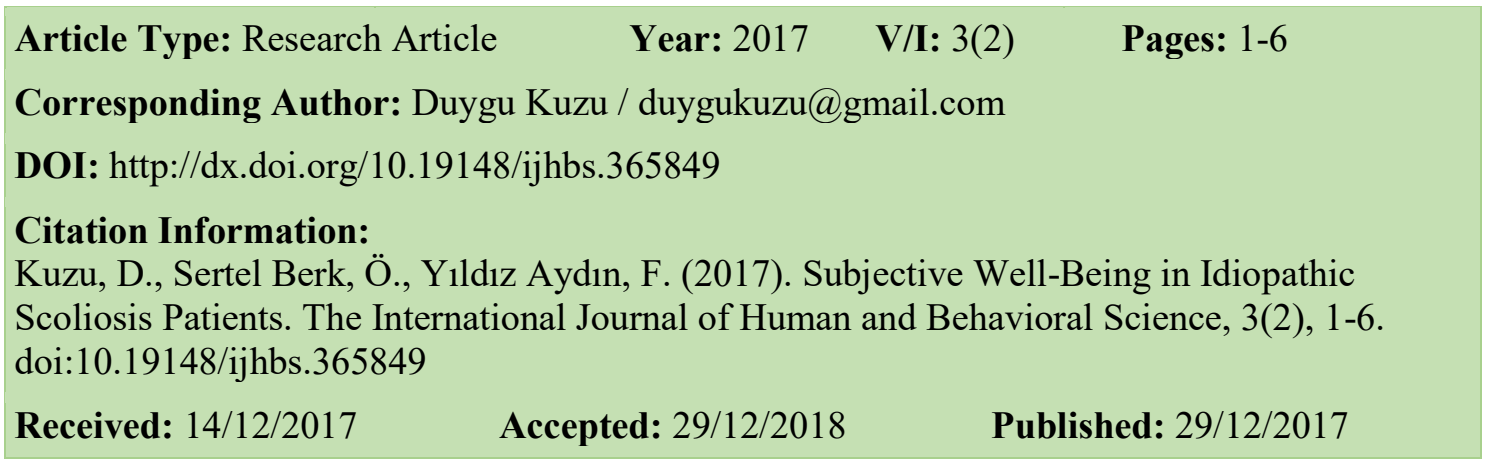

\title{
Subjective Well-Being in Idiopathic Scoliosis Patients
}

\author{
Duygu Kuzu, Istanbul University, Psychology,Turkey \\ ORCID: https://orcid.org/0000-0002-1134-1551 \\ Özlem Sertel Berk, Istanbul University, Psychology, Turkey \\ ORCID: https://orcid.org/0000-0002-3045-3903 \\ Filiz Yıldız Aydın, Department of Physical Therapy and Rehabilitation, Bakırköy Dr. Sadi Konuk \\ Training and Research Hospital, Turkey \\ ORCID: https://orcid.org/0000-0003-4763-7538
}

\begin{abstract}
The purpose of the present research was to examine the relationships between positive affect(PA), negative affect (NA), life satisfaction (LS) and scoliosis research society variables; image, pain, function and mental health. To determine whether PA, NA and LS predicted by image, pain, function and mental health a hierarchical regression analysis was specified. In the current study female scoliosis patients $(\mathrm{N}=83)$ completed three measures of positive and negative affect schedule (PANAS), Life satisfaction Scale and Scoliosis Research Society-22. Result showed that four factors accounted for subjective well-being variables (PA, NA, LS). The findings highlight the possibility that a consideration of subjective well-being for body image concerns.
\end{abstract}

Keywords: Idiopathic Scoliosis, Subjective Well-Being, Life Satisfaction, Body Image

\section{Introduction}

Idiopathic scoliosis is the three-dimensional pathology of the spine which shows a distinction from mild to severe curve. It leads to physical deformity among other psychological problems and also has effects on adolescents' self-esteem and self-image (Carraso \& Ruiz, 2014). Diagnostic criterion is having a Cobb Angle higher than 10 degrees in X-ray (Kotwicki, 2008).

Subjective well-being is considered as an individual's cognitive and affective assessments about their life in order to evaluate whether it is fulfilled or not. Having more pleasant emotions and less negative moods leads to having a more satisfactory life. The concept of SWB consists of three dimensions: Negative affect, positive affect and life satisfaction (Diener, Scollon \& Lucas, 2009). As well as subjective well-being was at first conceptualized as the balance between positive and negative affect (Bradburn, 1969) it also changes according to life changes and circumstances that people try to adopt to these circumstances (Heady \& Wearing, 1990). Many theories have tried to explain happiness. According to the goal satisfaction theory, people can only be happy when their sets of standards are met. For other researchers such as Michalos (2017), the discrepancy between what people have, what people want, what people had in the past and what other people around them have is related to happiness. Subjective well-being is also related to health. People who have subjective well-being have better health status than other people 
(Diener \& Chan, 2011). The definition of health according to WHO is "a state of complete physical, mental and social well-being and not merely the absence of disease and infirmity" (1958, p.459). Thus well-being is an important component of the health. In health literature, quality of life is mostly studied as health related quality of life. It refers to the subjective perception of disease while trying to improve well-being of patients which has reflection to general health. It also depends on four main domains that are physical/occupational functioning, social functioning, psychological well-being and physiological well-being (Fayers \& Machin, 2000). Thus instead of SWB, health quality of life is mostly studied with scoliosis patients. All four domains are affected for those patients. Even though the first diagnosis and treatment process is a stressful period for the patients with scoliosis regardless to treatment type (MacLean, Green, Pierre \& Ray, 1989), choosing the right type of treatment is also an important predictor for psychological well-being. While wearing a brace leads to great psychological stress for the patients especially in social settings (Matsunaga, Hayashi, Naruo, Nozoe \& Komiya, 2005), undergoing the surgery is another factor that affects life quality. Both brace and surgery treatments have negative impacts on the quality of life and psychological well-being. Patients who have undergone surgery, have some occupational disabilities (in terms of going to school or work, for instance) because of the surgery itself. And because of both surgery and brace treatments patients tend to attend social activities less frequently, and have more back pain problems compared to the healthy control group (Danielsson, Wiklund, Pehrsson \& Nachemson, 2001). All these results show that scoliosis effects the quality of life and has some negative impacts on the psychological condition. Due to the fact that there aren't any studies related to subjective well-being of scoliosis patients, the aim of this study is to evaluate the variables that affect life satisfaction, and positive and/or negative effects of scoliosis patients.

\section{Method}

Study is done by 83 volunteer idiopathic scoliosis patients and conducted in Istanbul Physical Medicine and Rehabilitation department of Bakirkoy Sadi Konuk Hospital and a special rehabilitation center. The inclusion criteria were having minimum 10 degree Cobb Angle idiopathic scoliosis and being over 14 years old). The study has been ethically approved by the Scientific Committee of Istanbul Arel University.

\subsection{Sample}

For the demographic variables, the study is composed of $68(82 \%)$ women and 15 men (18\%). $76 \%$ of them unmarried, and $46 \%$ of them higher educated. Their Cobb Angle change between $10-75(\mathrm{M}=27)$.

\subsection{Instrument}

\subsubsection{The Positive and Negative Affect Schedule}

The Positive and Negative Affect Schedule (PANAS) (Watson, Clark \& Tellegen, 1988). PANAS is 20 item scale that measure negative and positive affect. While 10 item is for positive affect the rest of them measure negative items and each of them is rated on 5-point scale, 1 (very slightly) to 5 (extremely). The coefficient alpha for positive mood was .87 , for negative mood is .91 in the original study. Thus PANAS is useful and valid tool for measuring mood states. The adaptation of the scale to Turkish was done by Gençöz (2000). Consistent with the original study factor analysis showed two factors accounting for $44 \%$ of the total variance and internal consistency value was .83 in the original study.

\subsubsection{Scoliosis Research Society-22 Patient Questionnaire}

Scoliosis Research Society-22 Patient Questionnaire (SRS-22), is a 22 item scale developed for scoliosis patients in order to measure their pain, function, self-image, mental health and satisfaction management. Original study is done in English by (Asher, Lai, Burton \& Manna, 2003) and Pearson's correlation coefficient was found .70 and alpha value is .92. Adaptation Turkish language of the scale was done by Alanay and colleagues (2005) and found Cronbach values for pain: .72, self-mage; .80, mental health: .72 and function for .48. Thus it was found to be reliable and valid questionnaire to use in Turkish language. 


\subsubsection{The Satisfaction with Life Scale}

The Satisfaction with Life Scale - SWLS: Life satisfaction was measured by Diener and colleagues' (1985) SWLS to identify individual differences concerning the cognitive evaluation of one's life. The scale is designed to understand individuals to evaluate their lives according to their own subjective criteria. SWLS was developed in order to see whether individuals are satisfied with their life in general or not. Durak and colleagues (2008) translated the scale into Turkish and reported satisfactory internal consistencies $(\alpha=.86, .82)$.

\subsection{Data Analysis}

All statistics were performed using SPSS 15 for Windows. Both correlation and regression analysis were run.

\section{Findings}

The correlations among the variables were presented in Table 1. Highest correlations were obtained between SRSpain and LS $(r=-.37, p<.001)$, SRSimage and PA, NA, LS $(r=-.39, .42$, $.43, p<.001)$, SRSmental and LS $(r=.50, p<.001)$.

Table 1: Correlations of SRS-22, PANAS and Life Satisfactions

\begin{tabular}{lccccccccc}
\hline Item & Mean & SD & SRSPAIN & SRSIMG & SRSFUNC & SRSMENT & PA & NA & LS \\
\hline SRSPAIN & 11.45 & 2.83 & - & & & & & & \\
SRSIMG & 13.30 & 3.94 & .29 & - & & & & \\
SRSFUNC & 15.30 & 2.14 & $.39^{* *}$ & $.29^{* *}$ & - & & & \\
SRSMENT & 15.20 & 1.57 & .13 & .15 & -.08 & - & & \\
PA & 33.60 & 7.40 & $-.25^{*}$ & $-.39^{* *}$ & -.13 & .03 & - & \\
NA & 23.15 & 6.03 & $.24^{*}$ & $.42^{* *}$ & .10 & $.23^{*}$ & -.14 & - \\
LS & 14.42 & 4.70 & $-.37^{* *}$ & $-.43^{* *}$ & -.16 & $.50^{* *}$ & $.50^{* *}$ & $.36^{* *}$ & - \\
\hline
\end{tabular}

Note. $N=83$, SRSPAIN= Scoliosis Research Society pain, $\mathrm{SRSIMG=} \mathrm{Scoliosis} \mathrm{Research} \mathrm{Society} \mathrm{image,}$ $\mathrm{SRSFUNC}=$ Scoliosis Research Society function, $\mathrm{SRSMENT}=$ Scoliosis Research Society mental health, $\mathrm{PA}=$ positive affect, $\mathrm{NA}=$ negative affect, $\mathrm{LS}=$ life satisfaction

$*_{p}<.05, * * p<.01$

In addition to correlation results regression analyses were run and the summary of regression analyses were presented in Table 2. It is clear from the results that the four factors accounted for $20 \%$ of the variance in PA while only SRSimage added to the variance explained $[\mathrm{F}(4,71)=4,51$; $\mathrm{p}<.05 ; \mathrm{t}=-3,50, \mathrm{~B}=-.67 ; \beta=-.40] \quad$. It is the same for NA that four factors accounted for $22 \%$ and SRSimage added to the variance explained $[\mathrm{F}(4,71)=5,00 ; \mathrm{p}<.05, \mathrm{t}=3,30 ; \mathrm{B}=.56 ; \beta=$ $.37]$. For the LS four factors accounted for $26 \%[\mathrm{~F}(4,72)=6,40 ; \mathrm{p}<.001 ; \mathrm{t}=-3,42, \mathrm{~B}=-.42 ; \beta=$ -.37 ] but in addition to SRSimage also SRS pain is added to the variance explained.

Table 2: Summary of Regression Analyses for Variables Predicting Understanding of Positive Affect, Negative Effect and Life Satisfaction

\begin{tabular}{|c|c|c|c|c|c|c|}
\hline & \multicolumn{2}{|c|}{ PA } & \multicolumn{2}{|c|}{ NA } & \multicolumn{2}{|c|}{ LS } \\
\hline Variables & B & $\beta$ & B & $\beta$ & B & $\beta$ \\
\hline SRSPain & -.38 & -.16 & .24 & .11 & -.40 & $-.24 *$ \\
\hline SRSimage & -.67 & $-.40 * *$ & .56 & $.37 * *$ & -.42 & $-.37 *$ \\
\hline SRSfunction & .20 & .06 & -.06 & -.02 & .10 & .04 \\
\hline SRSmental & .04 & .01 & .72 & .17 & -.31 & -.09 \\
\hline$R^{2}$ & \multicolumn{2}{|c|}{.20} & \multicolumn{2}{|c|}{.22} & \multicolumn{2}{|c|}{.26} \\
\hline Adjusted $R^{2}$ & \multicolumn{2}{|c|}{.15} & \multicolumn{2}{|c|}{.18} & \multicolumn{2}{|c|}{.22} \\
\hline F Change & \multicolumn{2}{|c|}{4.51} & \multicolumn{2}{|c|}{5.00} & \multicolumn{2}{|c|}{6.40} \\
\hline
\end{tabular}

Note. $N=83$, SRSPAIN= Scoliosis Research Society pain, $\mathrm{SRSIMG=} \mathrm{Scoliosis} \mathrm{Research} \mathrm{Society} \mathrm{image,}$ SRSFUNC $=$ Scoliosis Research Society function, SRSMENT $=$ Scoliosis Research Society mental health, $\mathrm{PA}=$ positive affect, $\mathrm{NA}=$ negative affect, $\mathrm{LS}=$ life satisfaction $* p<.05, * * p<.01, N=83$ 


\section{Discussion and Conclusion}

In this study multiple regression analysis was conducted and according the results, scoliosis patients' subjective well-being was affected mostly by their body-image. Even though it was found in the current research that pain factor contributes to life satisfaction, mostly self-image is accounted. All three components of subjective well-being imply (PA, NA and LS) the relationship of image concerns. Consistent with the literature, in the current research it was shown that body image concern is one of the main concerns that cause psychosocial problems. It is known that having low level of body image satisfaction often leads to impairment in social functioning, low self-esteem, low quality of life and depression (Cash, 2006). It is seen in scoliosis patients as well, mostly females, have less satisfaction with their body images and lives, and feel a lower level of happiness (Sapountzi-Krepia et al., 2001).. Even though the current study just emphasizes positive affect, negative affect and life satisfaction that shows the impairment in body image can cause other psychological problems too. Thus, in order to increase their life satisfaction and positive effect in this group, working on their self-image in clinical setting is crucial. Working on psychological aspects of scoliosis may contribute to the effects of treatment for both surgery and conservative treatments. Combining psychological interventions into the treatment process may reduce psychological problems in their life.

There are several limitations of the study that should be acknowledged. Firstly, there is not any participant that had surgery, so future work should focus on whether there is any change depends on body image and life satisfaction after surgical treatment. Both conservative and surgical treatment may itself have effects on improving body image and life satisfaction. The other limitation is as other scoliosis studies, there is not equal number of male and female participants. This limitation of the study makes it difficult to compare gender differences in psychological aspects of scoliosis. Additionally, future researchers should focus on developing instruments to assess scoliosis patients' life satisfaction rather than health related or general life satisfaction.

In conclusion, improving subjective well-being will contribute health promotion while preventing ill behavior. Preparing these kinds of intervention programs may contribute health promotion in multidisciplinary way. In the literature there are only a few studies that use cognitive behavioral interventions. They are targeting only pre-operative and post-operative patients in order to reduce their level of anxiety (LaMontagne, Hepworth, Cohen \& Salisbury, 2003, 2004). Those interventions may also be used just at the beginning of the diagnosis. And also a specific focus on treatment compliance and improvement of coping methods is necessary. In this way patients may learn how to cope with the diagnosis and all treatment processes. Both group and individual interventions can be adapted to scoliosis patients in order to improve treatment compliance and coping strategies for treatment. Further researchers should discuss specific interventions and conduct family based studies. 


\section{References}

Alanay, A., Cil, A., Berk, H., Acaroglu, R. E., Yazici, M., Akcali, O., et al (2005).Reliability and validity of adapted Turkish Version of Scoliosis Research Society-22 (SRS-22) questionnaire. Spine, 30(21), 2464-2468.

Asher, M., Lai, S. M., Burton, D., \& Manna, B. (2003). The reliability and concurrent validity of the scoliosis research society-22 patient questionnaire for idiopathic scoliosis. Spine, 28(1), 63-69.

Bradburn, N. M. (1969). The structure of psychological well-being. Chicago: Aldine.

Carrasco, M. I. B., \& Ruiz, M. C. S. (2014). Perceived self-image in adolescent idiopathic scoliosis: an integrative review of the literature. Revista da escola de enfermagem da USP, 48(4), 748-757.

Cash, T.F. (2006). Body image and plastic surgery. In D. B. Sarwer et al. (Eds), Psychological aspects of reconstructive and cosmetic surgery: Clinical, empirical, and ethical perspectives (pp. 37-59). Philadelphia: Lippincott, Williams \& Wilkins.

Danielsson, A. J., Wiklund, I., Pehrsson, K., \& Nachemson, A. L. (2001). Health-related quality of life in patients with adolescent idiopathic scoliosis: a matched follow-up at least 20 years after treatment with brace or surgery. European spine journal, 10(4), 278-288.

Diener, E., Napa Scollon, C., \& Lucas, R. E. (2009). The evolving concept of subjective wellbeing: The multifaceted nature of happiness. In Diener E. (Ed.), Assessing well-being (67-100). Netherlands: Springer.

Diener, E., \& Chan, M. Y. (2011). Happy people live longer: Subjective well-being contributes to health and longevity. Applied psychology: Health and Well-Being, 3(1), 1-43.

Durak, M., Gençöz, T., \& Senol-Durak, E. (2008). The reliability and validity of the satisfaction with life scale in the samples of Turkish elderly and correctional officers. In $I V$ European conference on positive psychology, Rijeka-Opatija, Crotia.

Fayers, P. M., \& Machin, D. (2000). Quality of life: Assessment, Analysis and Interpretation. West Sussex: John Wiley \& Sons Ltd.

Gençöz, T. (2000). Pozitif ve negatif duygu ölçeği: Geçerlik ve güvenirlik çalışması. Türk psikoloji dergisi, 15(46), 19-26.

Headey, B., \& Wearing, A. (1990). Subjective well-being and coping with adversity. Social Indicators Research, 22(4), 327-349.

Kotwicki, T. (2008). Evaluation of scoliosis today: examination, X-rays and beyond. Disability and Rehabilitation, 30(10), 742-751.

LaMontagne, L. L., Hepworth, J. T., Cohen, F., \& Salisbury, M. H. (2003). Cognitive behavioral intervention effects on adolescents' anxiety and pain following spinal fusion surgery. Nursing Research, 52(3), 183-190.

LaMontagne, L. L., Hepworth, J. T., Cohen, F., \& Salisbury, M. H. (2004). Adolescent scoliosis: effects of corrective surgery, cognitive-behavioral interventions, and age on activity outcomes. Applied Nursing Research, 17(3), 168-177.

MacLean Jr, W. E., Green, N. E., Pierre, C. B., \& Ray, D. C. (1989). Stress and coping with scoliosis: psychological effects on adolescents and their families. Journal of Pediatric Orthopaedics, 9(3), 257-261.

Matsunaga, S., Hayashi, K., Naruo, T., Nozoe, S. I., \& Komiya, S. (2005). Psychologic management of brace therapy for patients with idiopathic scoliosis. Spine, 30(5), 547550.

Michalos, A. C. (2017). Multiple discrepancies theory (MDT). In A. C. Michalos, Development of Quality of Life Theory and its Instruments (39-95). Cham: Springer International Publishing.

Sapountzi-Krepia, D. S., Valavanis, J., Panteleakis, G. P., Zangana, D. T., Vlachojiannis, P. C., \& Sapkas, G. S. (2001). Perceptions of body image, happiness and satisfaction in adolescents wearing a Boston brace for scoliosis treatment. Journal of advanced nursing, 35(5), 683-690. 
Watson, D., Clark, L. A., \& Tellegen, A. (1988). Development and validation of brief measures of positive and negative affect: the PANAS scales. Journal of Personality and Social Psychology, 54(6), 1063.

Weiss, H. R., Werkmann, M., \& Stephan, C. (2007). Brace related stress in scoliosis patients Comparison of different concepts of bracing. Scoliosis, 2(1), 10.

World Health Organization. (1958). The first ten years of the World Health Organization. Geneva: World Health Organization. 